\title{
IMPORTÂNCIA DA EDUCAÇÃO AMBIENTAL E MEIO AMBIENTE NA ESCOLA: UMA PERCEPÇÃO DA REALIDADE NA ESCOLA MUNICIPAL COMENDADOR CORTEZ EM PARNAIBA (PI)
}

Vera Lucia Tavares de Brito ${ }^{1}$

Lorran André Moraes²

Roselis Ribeiro Barbosa Machado ${ }^{3}$

Maria de Fátima Veras Araújo ${ }^{4}$

RESUMO - Nos últimos anos, a discussão sobre os problemas ambientais globais se intensificou, e a EA (Educação Ambiental) surgiu como resposta às necessidades a essas discussões, se tornando indispensável ser estudada nas escolas, como forma de assegurar um futuro equilibrado entre a humanidade e a existência do planeta. Este trabalho avalia a percepção sobre Educação Ambiental (EA) e meio ambiente de estudantes e professores na escola municipal Comendador Cortez, no município de Parnaíba - PI, diagnosticando ainda a forma como vem sendo trabalhada, o conhecimento que possuem sobre o assunto e como o recebem na referida escola. A metodologia utilizada foi a pesquisa bibliográfica e de campo, sobre informações do objeto de estudo. Através desta, constatou-se que a temática Educação Ambiental é trabalhada poucas vezes em sala de aula, de forma isolada, em algumas disciplinas, especialmente as relacionadas com o meio ambiente, sendo que a transversalidade exigida pelos documentos oficiais, como os PCNs, não acontece.

Palavras-chave: Educação Ambiental; Meio Ambiente; Escola.

1 Graduada em Ciências Biológicas pela Universidade Estadual do Piauí - UESPI, campus de Piracuruca - PI. Graduada em Pedagogia - UESPI.

2 Biólogo, Bi-graduado em Ciências Biológicas - UFPI e UESPI, Pós- graduado em Gestão e Educação Ambiental- UESPI, Pós- graduado em Biodiversidade e Conservação - UESPI, Pós- graduando em Gestão e Supervisão Escolar com docência do Ensino Superior - FAEME. Professor tutor do Curso de Pós-graduação em Gestão e Educação Ambiental do NEAD-UESPI. Email: Iorranbio@hotmail.com

${ }^{3}$ Bióloga, Doutora em Geografia/UFPE. Professora Adjunta III do Centro de Ciências da Natureza - CCN - UESPI. Coordenadora do Grupo de Pesquisa em Paisagismo e Meio Ambiente - NUPEMAP / UESPI.

4 Bióloga, Doutora em Geografia -UFPE. Professora Adjunta IV do Centro de Ciências da Natureza, CCN - UESPI. Colaboradora do grupo de Pesquisa em Paisagismo e Meio Ambiente -NUPEMAP -UESPI. 


\section{Introdução}

Há muito tempo existem preocupações acerca de como analisar, solucionar e prevenir problemas inerentes à dinâmica ambiental. Entretanto, é somente no contexto contemporâneo que tais preocupações ganham, progressivamente, maior projeção, forçando-nos a reconhecer que vivenciamos uma crise ambiental sem precedentes (MAKNAMARA, 2009). Os questionamentos acerca da crise ambiental ora vivenciada e as diferentes concepções acerca do que vem a ser Ambiente têm apresentado repercussão direta no campo educacional, materializando-se num conjunto altamente diversificado de reflexões e práticas que, apesar de abrangerem a questão ambiental de maneira bastante diferenciada, são agrupadas em torno do que se costuma denominar de Educação Ambiental (SOUSA; FERNANDES, 2015).

A educação formal exerce o papel de preparar o educando a aprender, a respeitar o próximo, a natureza, enfim a vida, pois através da educação se aprende a ser ético, humano, aprende a viver em grupo e a lutar pelo seu bem e dos demais (SÁ; OLIVEIRA; NOVAES, 2015). A educação hoje pode ser o principal passo para conduzir o rumo que o futuro habitante da terra terá (OLIVEIRA, 2012).

Diante da necessidade de formação de cidadãos conscientes sobre a conservação do ambiente, é necessária a implementação de projetos de Educação Ambiental, com uma visão crítica e diferenciada do pensamento ideológico, puramente utópico que tem dominado a Educação Ambiental tradicional (GUIMARÃES, 2007).

Para Jaspers (1993, p. 30), "o colapso do sentido de duração do mundo material solapa a circunstância humana e ameaça o próprio homem". O paradigma do imediatismo precisa ser pensado, o futuro da espécie humana depende de atitudes conscientes agora.

Assim, a escola é um espaço privilegiado para estabelecer conexões e informações, como uma das possibilidades para criar condições e alternativas que estimulem os alunos a terem concepções e posturas cidadãs, cientes de suas responsabilidades e, principalmente, perceberem-se como integrantes do meio ambiente (SOUSA; FERNANDES, 2015). A educação formal continua sendo um espaço importante para o desenvolvimento de valores e atitudes comprometidas com a sustentabilidade ecológica e social (LIMA, 2004).

Dessa forma, este trabalho avaliou a percepção sobre Educação Ambiental (EA) e meio ambiente de estudantes e professores na escola municipal Comendador Cortez, no município de Parnaíba (PI), diagnosticando ainda a forma como vem sendo trabalhada, o conhecimento que possuem sobre o assunto e como o recebem na referida escola. 


\section{Revisão de literatura}

Sabe-se que a EA (Educação Ambiental) surgiu como resposta às necessidades que não estavam sendo completamente correspondidas pela educação formal. Em outras palavras, a educação deveria incluir valores, capacidades, conhecimentos, responsabilidades e aspectos que promovessem o progresso das relações éticas entre as pessoas, seres vivos e a vida no planeta. No entanto, o problema do descuido com o meio ambiente, constitui uma das questões sociais que tem deixado a humanidade preocupada, por isso, talvez, seja um dos fatores, mais relevantes, a serem estudado nas escolas, porque tem a ver com o futuro da humanidade e com a existência do planeta. (MEDEIROS et al., 2011).

Segundo a UNESCO (2005, p. 44), "Educação Ambiental é uma disciplina bem estabelecida que enfatiza a relação dos homens com o ambiente natural, as formas de conservá-lo, preservá-lo e de administrar seus recursos adequadamente".

A definição oficial de Educação Ambiental, do Ministério do Meio Ambiente é: "Educação Ambiental é um processo permanente, no qual os indivíduos e a comunidade tomam consciência do seu meio ambiente e adquirem conhecimentos, valores, habilidades, experiências e determinação que os tornam aptos a agir - individual e coletivamente - e resolver problemas ambientais presentes e futuros" (BOSA; TESSER, 2014).

Para Antunes (2004, p.8), o conceito de Educação Ambiental baseia-se em uma prática de educação para a sustentabilidade, sendo a tradução das relações humanas com o ambiente. É também um processo contínuo de ajuda ao ser humano na identificação dos sintomas e das causas reais dos problemas ambientais e procura ainda desenvolver conhecimentos, aptidões, atitudes, motivações e a disposição necessária para o trabalho individual e coletivo na busca de soluções.

Já Meirelles e Santos (2005, p.34) afirmam que a Educação Ambiental é uma atividade meio que não pode ser percebida como mero desenvolvimento de "brincadeiras" com crianças e promoção de eventos em datas comemorativas ao meio ambiente. Na verdade, as chamadas brincadeiras e os eventos são parte de um processo de construção de conhecimento que tem o objetivo de levar a uma mudança de atitude. $O$ trabalho lúdico, reflexivo e dinâmico respeita o saber anterior das pessoas envolvidas (CARDOSO; FRENEDOSO; ARAÚJO, 2015).

Para tanto, se faz necessário a realização de estudos sobre os problemas ambientais, conscientizando e propondo estudos sobre a importância da inclusão de questões ambientais e sociais no currículo escolar a partir da transversalidade. Autores como Zuben (1998), Britto (2000), Guimarães (2005), entre outros, contribuem para a discussão dessa temática.

Nas sociedades atuais o ser humano afasta-se da natureza, e age de forma irresponsável em relação ao meio ambiente, causando grandes desequilíbrios na natureza. Segundo Guimarães (2005), é pela gravidade da Revbea, São Paulo, V. 11, № 2: 22-42, 2016. 
situação ambiental, em todo o mundo, que se tornou necessário a implantação da Educação Ambiental para as novas gerações em idade de formação de valores e atitudes, como também para a população em geral, pela emergência da situação em que nos encontramos.

É nessa perspectiva, que o autor afirma que a Educação Ambiental é transformadora de valores e atitudes através da construção de novos hábitos e conhecimentos, conscientizadora para as relações integradas do ser humano, sociedade, natureza objetivando o equilíbrio local e global, melhorando a qualidade de todos os níveis de vida (GUIMARÃES, 2005, p.17).

A EA busca assegurar que o futuro do planeta esteja equilibrado no que se refere à natureza. A sua Política Nacional, instituída pela Lei $\mathrm{n} \cong 9.795$ de 27 de abril de 1999, tem como um de seus princípios o pluralismo de ideias e concepções pedagógicas na perspectiva da interdisciplinaridade. Esta lei determina que a EA não seja trabalhada na forma de disciplina especifica, mas que permeie o currículo das disciplinas.

\section{Educação Ambiental na Lei}

A Lei no 9.795/99 especifica sobre o tratamento e a disposição da Educação Ambiental, instituindo a Política Nacional de Educação Ambiental, a qual deve estar presente dentro de todos os níveis educacionais, com o objetivo de atingir todos os alunos em fase escolar.

A lei reafirma o direito à Educação Ambiental a todo cidadão brasileiro comprometendo os sistemas de ensino a provê-la no âmbito do ensino formal. Em outras palavras, poderíamos dizer que todo aluno na escola brasileira tem garantido esse direito durante todo o seu período de escolaridade. (LAYRARGUES, 2004).

Os PCNs (Parâmetros Curriculares Nacionais) vêm fortalecer para os professores a importância de trabalhar a EA como forma de transformação da conscientização dos indivíduos, sendo uma forma de integrar as diversas áreas do conhecimento. Porém, em nosso país a realidade diverge do que determina a lei (OLIVEIRA; SAITO, 2014). O caráter integrador do meio ambiente acaba permanecendo na teoria, o que vem reforçar a ideia antropocêntrica de grande parte da sociedade: o homem não faz parte do meio ambiente, ele está fora do mesmo, e muitas vezes, considera-se como superior (CARDOSO; FRENEDOSO; ARAÚJO, 2015).

Para Antunes (2004), a EA baseia-se em uma prática de educação para a sustentabilidade, sendo a tradução das relações humanas com o ambiente. É também um processo contínuo de ajuda ao ser humano na identificação dos sintomas e das causas reais dos problemas ambientais. Procura ainda desenvolver conhecimentos, aptidões, atitudes, motivações e a disposição necessária para o trabalho individual e coletivo na busca de soluções. 
Já para Morales (2004), a EA é a condição básica para alterar um quadro crítico, perturbador e desordenado recheado de crescente degradação socioambiental, mas que isoladamente não é suficiente para tanto. Portanto, não deve ser vista como o único caminho a ser trilhado, porém ela interrompe como mais um importante caminho de mediação na relação sociedade Inatureza, buscando construir uma sociedade sustentável que privilegie a racionalidade e o saber socioambiental.

Inúmeras reflexões acerca dessa temática têm se pautado, segundo Jacobi (2003), pela permanente degradação do meio ambiente e dos seus ecossistemas, tornando cada vez mais evidente a necessidade do desenvolvimento de uma Educação Ambiental articulada, envolvendo um conjunto de atores sociais do universo educativo e potencializando o engajamento das diversas fontes de conhecimento, além da necessária capacitação profissional e da comunicação didático pedagógica.

Educação Ambiental é o nome que historicamente se convencionou dar às práticas educativas relacionadas à questão ambiental. Assim, "Educação Ambiental" designa uma qualidade especial que define uma classe de características que, juntas, permitem o reconhecimento de sua identidade, [...] desde que se cunhou o termo Educação Ambiental, diversas classificações e denominações explicitaram as concepções que preencheram de sentido as práticas e reflexões pedagógicas relacionadas à questão ambiental (LAYRARGUES, 2004, p. 7).

Assim, a Educação Ambiental pode ser entendida como um processo participativo, no qual o educando assume o papel de elemento central do processo de ensino/aprendizagem pretendido, participando ativamente do diagnóstico de problemas ambientais, buscando as suas soluções, preparandose para se tornar agente transformador das atuais condutas populares, através do desenvolvimento de habilidades e da formação de atitudes, ou através de uma conduta ética condizente ao exercício da cidadania. Nesta temática, a EA constituiu-se em uma forma abrangente de educação, cuja proposta visa atingir todos os cidadãos, com um processo pedagógico e participativo permanente, procurando incutir no educando uma consciência crítica sobre a problemática ambiental, compreendendo-se como crítica a capacidade de captar a gênese e a evolução de problemas ambientais (SOUSA, 2007).

\section{Escola como espaço de Educação Ambiental}

Uma Educação Ambiental que se queira eficiente, segundo Layrargues (2004), deve ter uma concepção crítica objetivando promover ambientes educativos de mobilização, realizando e promovendo intervenções, tanto sobre a realidade como sobre os problemas socioambientais em que indivíduo e sociedade estejam inseridos, visando à formação para o exercício de uma cidadania ativa na transformação da atual realidade socioambiental. 
Nesse sentido, torna-se imprescindível a promoção de ações pedagógicas que superem a mera transmissão de conhecimentos ecologicamente corretos, mas que provoquem a sensibilização dos indivíduos quanto às causas ambientais (LAYRARGUES, 2004). São ações em que deve predominar a associação entre o aspecto cognitivo e o afetivo dos educandos no cotidiano escolar, através, principalmente, da vivência prática acerca dos temas da Educação Ambiental.

\section{Materiais e métodos}

\section{Caracterização da área de estudo}

O município de Parnaíba situa-se no extremo Norte do Estado do Piauí, localiza-se a $339 \mathrm{~km}$ da capital, Teresina, com uma área de $436 \mathrm{~km}$, apresentando uma população de 148.832 hab. e taxa de alfabetização de $98,8 \%$ (IBGE, 2015).

A Escola Municipal Comendador Cortez, com 14 anos de existência, está localizada na zona urbana do município de Parnaíba, Piauí, a $339 \mathrm{~km}$ da capital, Teresina, bairro Igaraçu, e funciona no turno da manhã com turmas de ensino fundamental menor, turno da tarde com turmas de ensino fundamental maior e a noite com turma de EJA (Educação de jovens de adultos). A escola conta com uma estrutura de 09 salas de aula, 410 alunos, 38 funcionários, dentre esses, 24 professores.

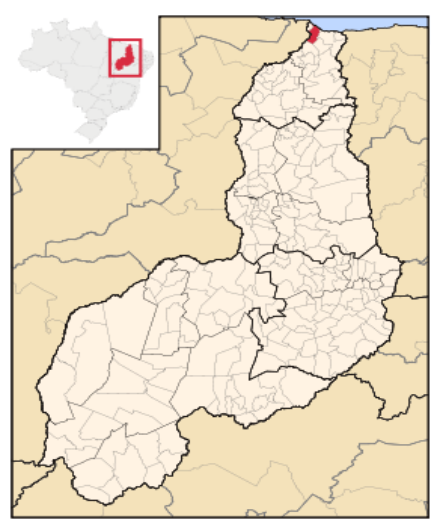

Figura 1: Localização do município de Parnaíba (PI). Fonte: IBGE, 2015

\section{Coleta de dados}

A pesquisa caracteriza-se como bibliográfica e de campo, através de questionários, para obter informações sobre a Educação Ambiental na escola pública municipal Comendador Cortez na cidade de Parnaíba (PI).

O presente trabalho partiu de uma revisão bibliográfica, em seguida diagnosticou a situação do ensino da Educação Ambiental na escola pública. 
Inicialmente, realizou-se pesquisa em (monografias, dissertações, teses, artigos e revistas cientificas) sobre o tema Educação Ambiental para fundamentar os objetivos pretendidos neste artigo.

Posteriormente foi visitada a escola municipal Comendador Cortez, na zona urbana de Parnaíba - PI, para possibilitar um contato e aproximação principalmente para conversar com a coordenadora, explicar o objetivo do trabalho, solicitar a autorização para realização da pesquisa e agendar a segunda visita.

Para coleta de dados elaboraram-se os questionários semiestruturados, com questões objetivas sobre o tema Educação Ambientais, que foram aplicados no mês de março de 2015 aos participantes da pesquisa (professores e alunos). Foram selecionados aleatoriamente 80 alunos entre as sete turmas de $6^{\circ}$ ao $9^{\circ}$ ano, do ensino fundamental. Essas perguntas se referiam de um modo geral sobre os aspectos ambientais como, por exemplo: sua importância, como eles são abordados na escola, quais atividades seriam mais viáveis para tratar do assunto, quais problemas cada entrevistado considera mais grave na cidade.

As observações buscaram, sobretudo, informações relacionadas ao espaço ambiental, ao comportamento socioambiental dos atores - professores e alunos, nesse espaço e ambiência cotidiana.

\section{Análise dos dados}

Após a coleta e seleção dos dados, estes foram tratados e analisados qualitativamente. Os critérios de seleção dos dados foram definidos, levandose em consideração as respostas que cada participante apresentou em cada questão, tirando-se assim a porcentagem geral. Para quantificar os dados dos questionários, foram elaboradas planilhas no Excel 2010. Para expressar os dados analisados foram elaborados gráficos como forma de facilitar a compreensão das questões individualmente.

\section{Resultados e discussão}

Feita a apresentação dos procedimentos operatórios desta investigação, passou-se, a partir de então, à análise e discussão de alguns pontos específicos a serem considerados, como seguem:

Com relação à identificação dos alunos em relação ao sexo, $57,5 \%$ são representados pelo sexo feminino e $42,5 \%$ do sexo masculino. A idade dos entrevistados ficou entre 11 e 16 anos. Tempo em anos que os alunos estudam na escola é de $10 \%$ até um ano, $25 \%$ de um a dois anos, $25 \%$ de 2 a 3 anos, $40 \%$ mais de 3 anos.

$\mathrm{Na}$ questão de número 1, que indagou: Você sabe o que é meio ambiente? Foi analisada de acordo com a metodologia baseada na interação socioambiental proposta por Lopes (1997) o qual prevê a possibilidade de avaliar os níveis de consciência de uma sociedade através de práticas 
contemplativas e comunicativas, que devem expressar os mais profundos pensamentos humanos na interação com seu meio.

A partir dos dados analisados na questão 1, percebeu-se que o conceito de meio ambiente é bem conhecido pelos alunos, pois $100 \%$ responderam que sabem sim o que é meio ambiente.

Na questão 2: Você se considera parte do meio ambiente? Observou-se que $90 \%$ dos alunos, se consideram inseridos no meio ambiente, e apenas 2,5 $\%$ não se consideram inseridos, e não souberam responder 7,5\% (Figura 2).

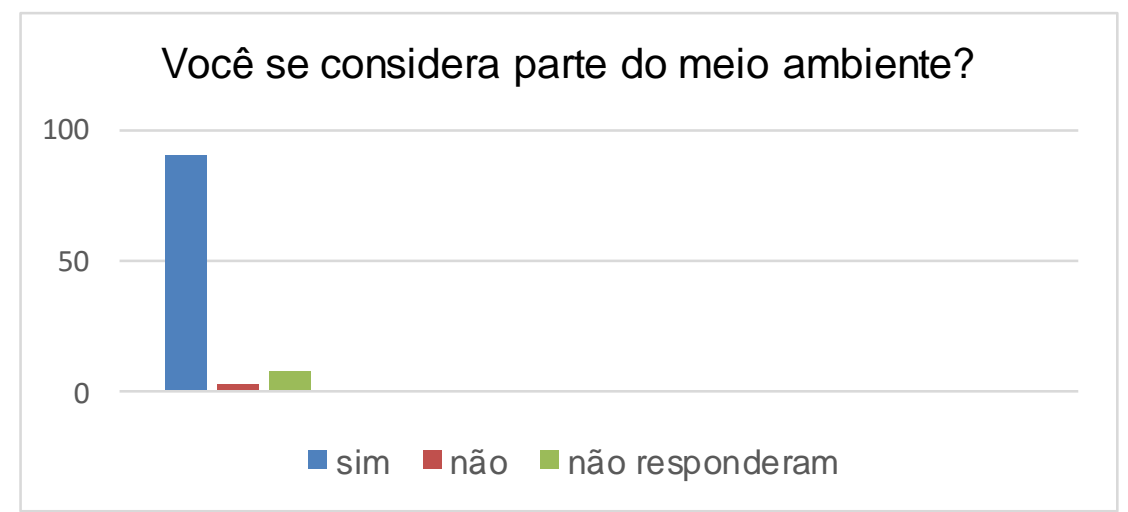

Figura 2: Porcentagem de alunos da Escola Municipal Comendador Cortez, Parnaíba (PI) que se consideram parte do meio ambiente, 2015.

Verificou-se, assim, a consciência da maioria sobre o entendimento de um conceito qual do homem também faz parte.

Em relação à percepção ambiental da cidade em que o aluno mora, quando perguntado sobre a questão: Onde você mora o ambiente é cuidado? $52,5 \%$ afirmaram que há sim um cuidado ambiental, 32,5\% que não há um devido cuidado e $12,5 \%$ não souberam responder.

Já em outra questão: Para você é importante que existam lugares em que o meio ambiente e a natureza estejam mais protegidos? $95 \%$ alegam que sim, 2,5\% afirmam que não e apenas 2,5\% não souberam responder.

Com base nesses dados, é possível perceber que os estudantes estão se importando com a preservação do ambiente, seja por meio do incentivo escolar ou de contextos externos, como influência da mídia visual e auditiva.

Quando se perguntou aos alunos se eles já ouviram falar sobre Educação Ambiental, 90\%, responderam que sim e apenas $10 \%$ citam que nunca ouviram.

$\mathrm{Na}$ questão 4, perguntou-se: já participaram de projetos que cuidam das questões ambientais? Nessa indagação $77,5 \%$ responderam que já participaram de alguma atividade nessa área, e apenas $22,5 \%$ nunca 
participaram (Figura 3). Segundo a UNESCO (2005, p. 44), "Educação Ambiental é uma disciplina bem estabelecida que enfatiza a relação dos homens com o ambiente natural, as formas de conservá-lo, preservá-lo e de administrar seus recursos adequadamente".

Portanto, incluindo a EA na escola pode-se preparar o indivíduo para exercer sua cidadania, possibilitando a ele uma participação efetiva nos processos sociais, culturais, políticos e econômicos relativos à preservação do verde no nosso planeta, que se encontram de certa forma em crise, precisando de recuperação urgente. $O$ início do processo de conscientização de que o meio ambiente requer é o entendimento e a reflexão de uma condição básica para a convivência humana. A EA tem muito a contribuir no sentido de construir relações e proporcionar intercâmbios entre as diversas disciplinas. Este intercâmbio depende exclusivamente da vontade dos docentes em participar deste processo, e que esta vontade dificilmente acontece sem haver uma orientação e um preparo.

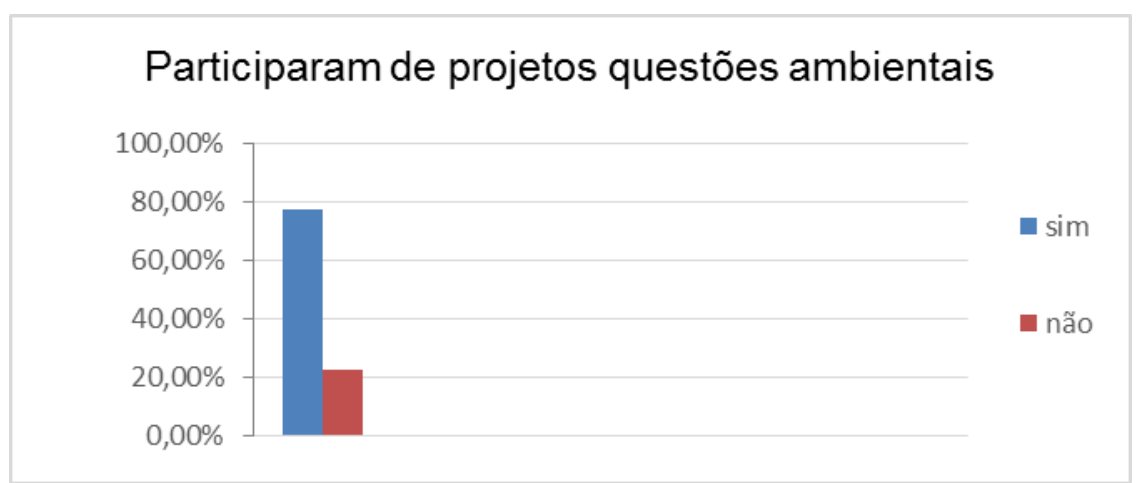

Figura 3: Porcentagem de alunos da Escola Municipal Comendador Cortez em Parnaíba (PI) que já participaram de projetos que abordam as questões ambientais, 2015.

Comparando as duas questões, pode-se perceber que os professores repassam as informações para os alunos, mas não há um trabalho sistêmico, há mais teoria do que prática.

$\mathrm{Na}$ questão 5 , sobre a importância das atividades de Educação Ambiental propostas na escola, $85 \%$ responderam que as atividades são muito importantes, enquanto $7,5 \%$ disseram que têm pouca importância e $7,5 \%$ disseram que é regular e não houve como resposta a opção sobre nenhuma importância (Figura 4). 


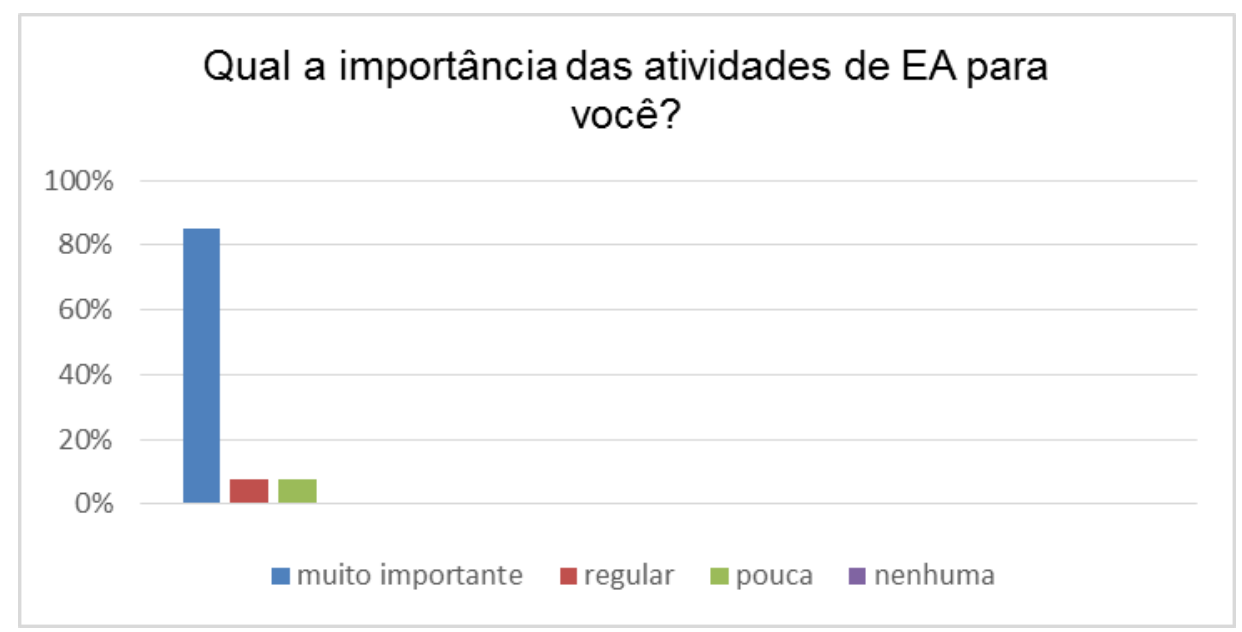

Figura 4: Concepção do nível de importância das atividades de EA dos alunos da Escola Municipal Comendador Cortez, Parnaíba (PI), 2015.

Consideravelmente, o resultado demonstra que o assunto é sim de grande importância segundo a maioria dos adolescentes. Entende-se que a maioria está ciente da importância de educar-se perante as necessidades ambientais.

$\mathrm{Na}$ questão 6, foram questionados sobre a frequência com que os professores abordam o tema Educação Ambiental (EA) em sala de aula. Dessa questão, obteve-se $67,5 \%$ que o assunto é trabalhado poucas vezes,15\% é trabalhado mensalmente, $12,5 \%$ semanalmente, $2,5 \%$ disseram que o assunto EA nunca é abordado, e 2,5\% não opinaram (Figura 5).

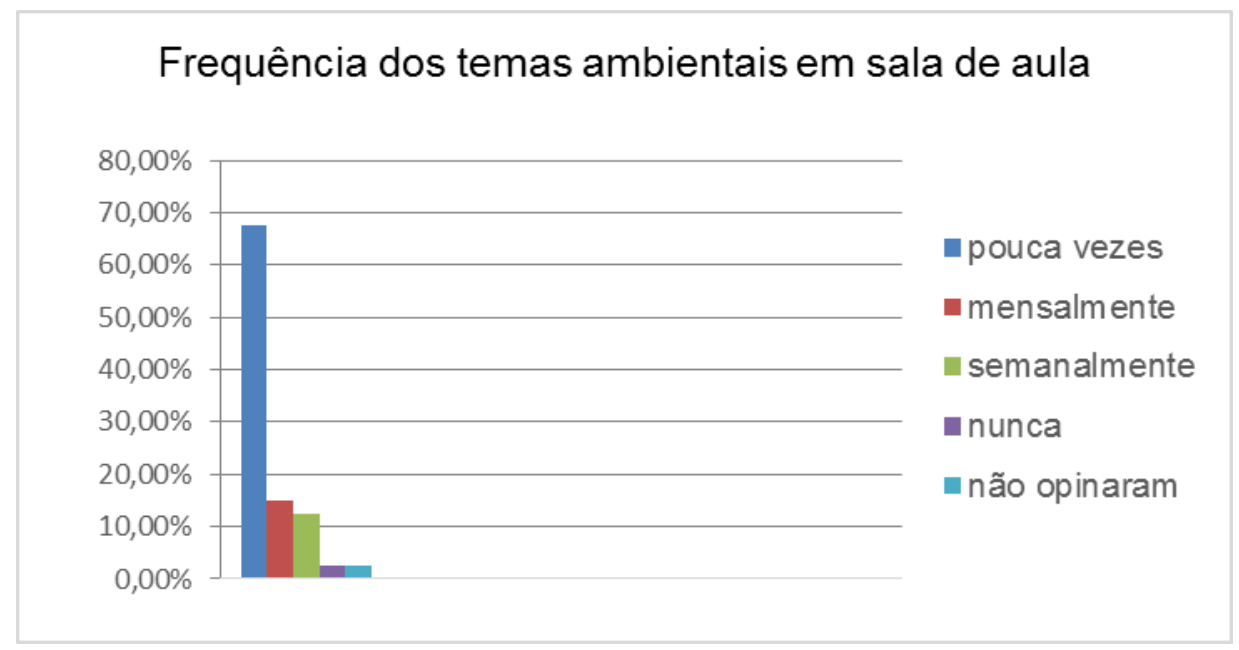

Figura 5: Visão dos alunos sobre a frequência de abordagem de temas ambientais pelos professores em suas aulas na Escola Municipal Comendador Cortez, Parnaíba (PI), 2015.

Revbea, São Paulo, V.11, № 2: 22-42, 2016.

revista brasileira educação ambiental 
Conforme a Figura 5, verifica-se que a maioria dos alunos responderam que o tema Educação Ambiental é trabalhado poucas vezes em sala de aula. E como a escola tem função educadora, a EA deveria ser levada a sério e trabalhada constantemente.

No que se refere à questão 7 , sobre a orientação quanto á separação e coleta do lixo produzido nas dependências da escola, $87,5 \%$ dos alunos responderam que são orientados, enquanto $10 \%$ responderam que não são orientados, e 2,5\% não responderam.

Apesar da maioria dos alunos informarem que o tema Educação Ambiental é trabalhado poucas vezes em sala de aula, os mesmos afirmam que recebem orientações específicas quanto a coleta seletiva do lixo gerado nas dependências da escola.

Um ponto importante da pesquisa foi a questão número oito que perguntava em quais disciplinas a Educação Ambiental é discutida na escola. 45\% disseram ser em Ciências, 37,5\% Geografia, 12,5\% dizem trabalhar em Português e $5 \%$ alegam não ser trabalhado esse assunto em nenhuma disciplina.

Dentre várias formas possíveis de se trabalhar a Educação Ambiental, os Parâmetros Curriculares Nacionais (PCN's) afirmam ser a interdisciplinaridade essencial ao desenvolvimento de temas ligados ao Meio Ambiente, sendo necessário desfragmentar os conteúdos e reunir as informações dentro de um mesmo contexto, nas várias disciplinas.

Perante as respostas, evidenciou-se que mesmo sendo um assunto de fácil interdisciplinaridade, ainda fica sendo de responsabilidade das disciplinas de Ciências e Geografia.

Quando foi solicitado na questão 9, para que os alunos citassem quais atividades eles acham mais adequadas para tratar de Educação Ambiental na escola, obteve-se, numa maioria, com $85 \%$ das respostas, as palestras, $12,5 \%$ debates e 2,5\% acham que filmes são os mais adequados e ninguém optou por outras formas, demonstração na (Figura 6). Aqui percebe-se que não existe diversificação para trabalhar essas questões com os alunos. Fica a ideia da mesmice. É claro que toda forma é interessante, desde que bem objetivada, mas a ideia nessa questão era saber se existe inovação dentre essas atividades e pelo comprovado nenhum aluno relatou alguma outra ideia. 


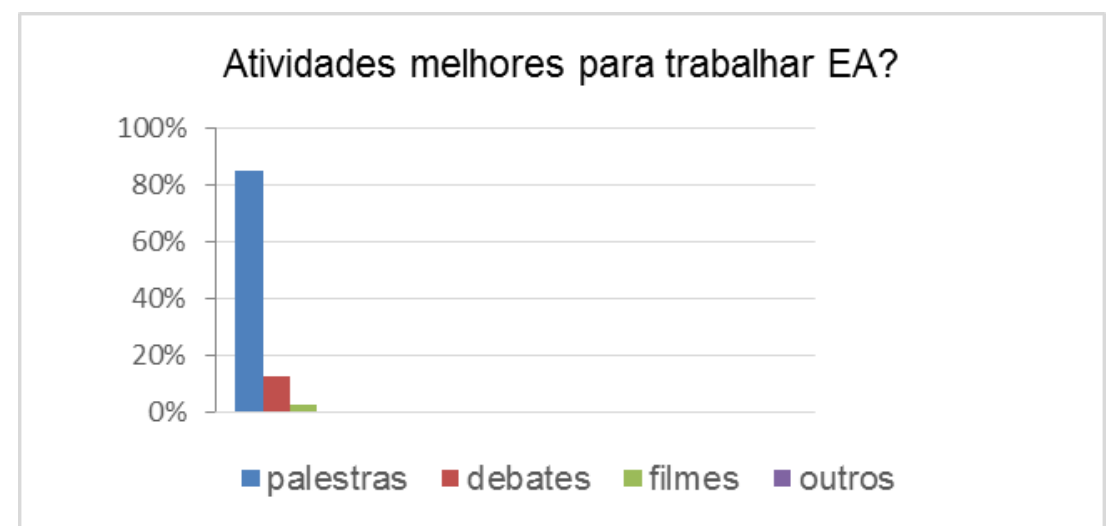

Figura 6: As melhores atividades para trabalhar a Educação Ambiental na visão dos alunos da Escola Municipal Comendador Cortez - Parnaíba (PI), 2015.

Na questão 10, indagou-se sobre o conhecimento que os adolescentes têm sobre os problemas ambientais na cidade onde residem, $95 \%$ dos alunos disseram conhecer, contra apenas $5 \%$ que alegaram não estarem a par dentro dessas informações. Aprofundou-se o questionamento sobre quais problemas ambientais que eles identificavam, na sua cidade, podendo citar mais de uma resposta, obteve-se um total $75 \%$ lixo nas ruas, citaram queimadas $20 \%$, desmatamento $7,5 \%$, e ainda poluição sonora com 2,5\% (Figura 7 ).

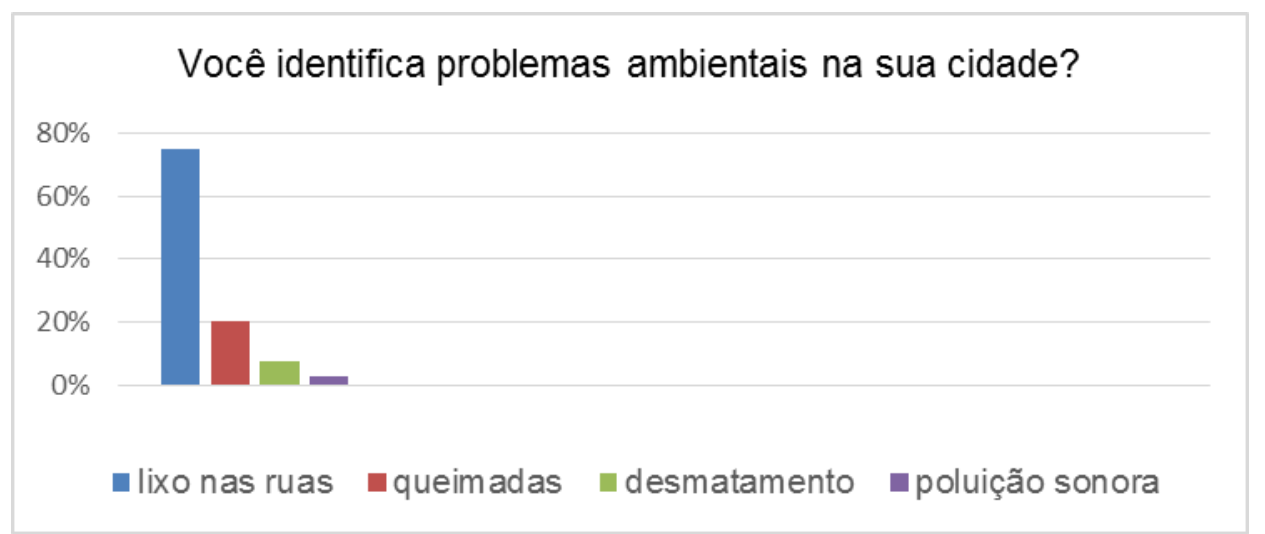

Figura 7: Os principais problemas ambientais ocorrentes na cidade na visão dos alunos da Escola Municipal Comendador Cortez - Parnaíba (PI), 2015.

De acordo com Otero e Neiman, (2015), a Educação Ambiental por se tratar de um processo permanente, está em curso, e enfrenta desafios, devendo abordar questões emergentes com relação à segurança climática, acidentes ambientais, entre outros. Porém, é preciso considerar que 20 anos é pouco para que as mudanças culturais e transformadoras da sociedade estejam plenamente implantadas, pois internalizar a consciência desenvolvida e transformá-la em mudança de fato é um processo a ser construído a longo prazo. 
Outro aspecto relevante é que, embora seja generalizada a concordância quanto a existência de uma crise ambiental e social contemporânea, é notório que os entendimentos sobre as causas e soluções para esta sejam, muitas, divergentes. Cremos, por fim, que a Educação Ambiental vem influenciando o pensamento e a vida dos brasileiros, e deve seguir adiante a tarefa mais difícil dos educadores ambientais: sua própria superação enquanto agente transformador da sociedade Otero e Neiman, (2015).

Os resultados mostraram que falta uma maior conscientização acerca dos reais motivos geradores de degradação ambiental, pois os sujeitos percebem o lixo nas ruas como sendo o maior agressor do ambiente em que vivem.

O lixo é citado entre os maiores problemas ambiental na comunidade, percebe-se também que está presente na escola, pois esse é um ambiente que produz grande quantidade de lixo. Assim, pela importância que a instituição escolar tem na formação de cidadãos mais responsáveis e conscientes "o lixo" foi citado pelos alunos como principal problema ambiental.

$\mathrm{Na}$ questão 11, quando indagados sobre como ficam sabendo de informações sobre o meio ambiente, $35 \%$ afirmaram saber através de jornais, $32,5 \%$ internet, $17,5 \%$ livros, e $15 \%$ relatam saber por outros meios de informação (Figura 8).

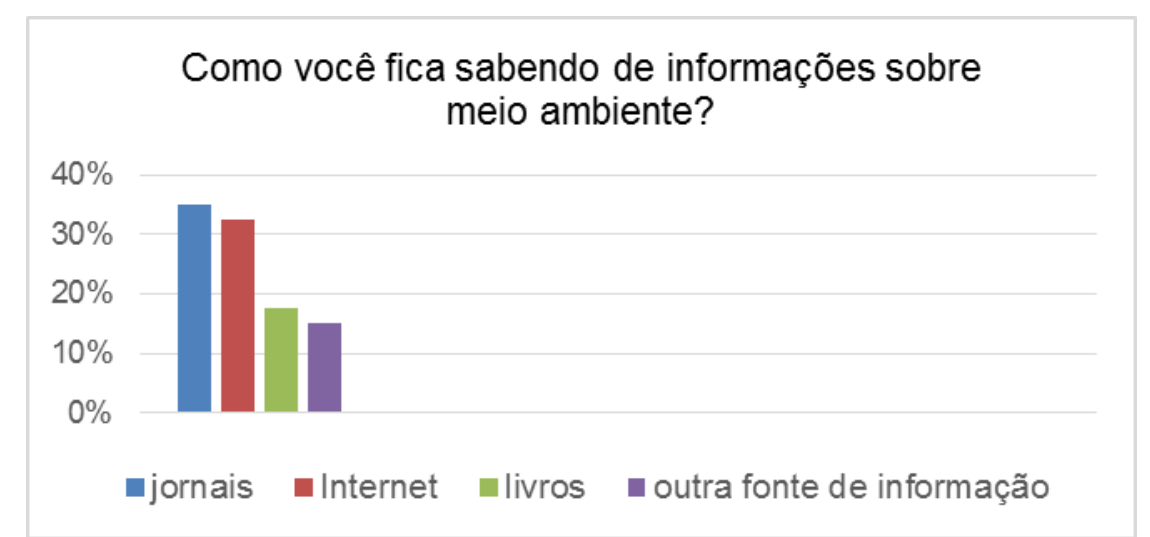

Figura 8: As principais fontes de informações dos alunos da Escola Municipal Comendador Cortez em Parnaíba (PI) sobre EA e meio ambiente da, 2015.

Conforme as respostas da figura 8 , observa-se que a maioria dos alunos fica informada sobre o Meio Ambiente, através de jornais e internet, deixando claro que existem outras fontes de informações tão relevantes quanto os livros. Cabe aos professores aproveitarem esses novos recursos, que são extremamente importantes para a formação dos educandos.

Para análise da percepção da Educação Ambiental por parte dos docentes, traçou-se um perfil daqueles que participaram da pesquisa, com 
relação a sexo, idade, escolaridade e tempo de atuação na área. Sendo que $83,3 \%$ dos professores que participaram da pesquisa são do sexo feminino, demonstrando assim a predominância desse sexo na docência de Ensino fundamental.

Com relação à faixa etária dos professores, percebe-se que um percentual considerável de $83,3 \%$ estão entre de 31 e 40 anos de idade, o que pode indicar um nível de maturidade maior. No quesito escolaridade, pode-se observar que $100 \%$ dos professores da referida escola são especialistas. Com relação ao tempo de atuação na área, $66,5 \%$ dos professores atuam há mais de 10 anos, 25\% entre 6 e 10 anos e apenas 8,5\% atuam de 1 a 5 anos (Figura 9). Observa-se que a maioria atua há mais de dez anos. Esses dados são relevantes considerando o grau de conhecimento, habilidades e atitudes dos professores, adquiridos nesse período.

Observou-se, ainda, de acordo com suas respostas que os professores possuem conhecimento sobre Educação Ambiental, sendo que a maioria dos professores conceituaram EA de uma forma mais adequada, como, por exemplo: "Educação Ambiental é a mudança de hábitos e atitudes com o objetivo de preservar o meio ambiente".

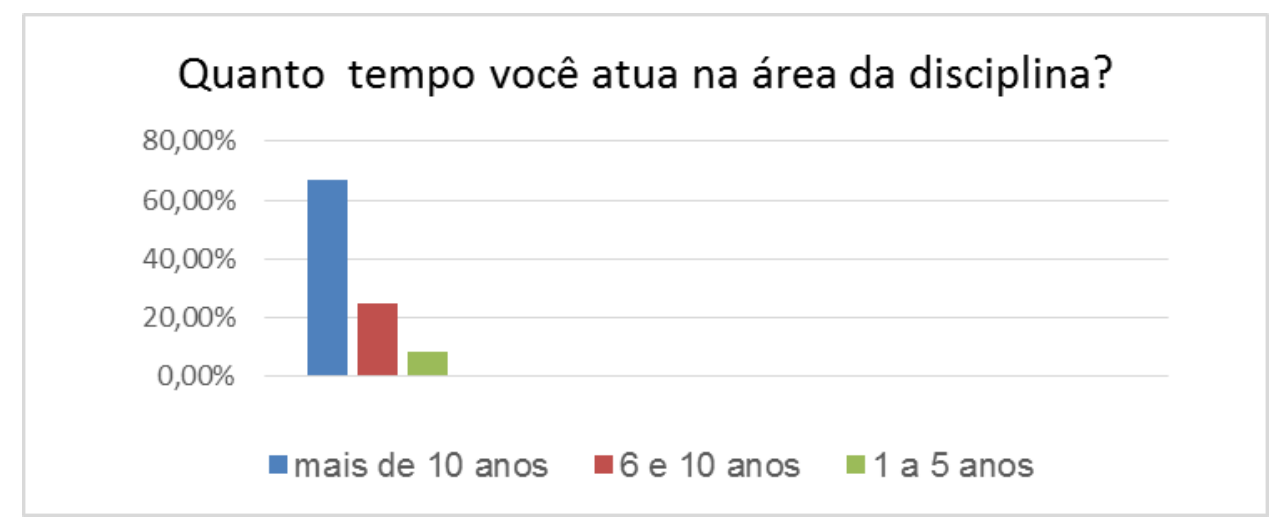

Figura 9: Tempo de atuação dos professores na área de ensino na Escola Municipal Comendador Cortez em Parnaíba (PI), 2015.

Quando se remete à questão 2, quanto ao desenvolvimento de projetos na escola, os professores foram unânimes em afirmar que a escola não desenvolve projetos de EA.

$\mathrm{Na}$ questão 3, referente à importância de inserir a temática da Educação Ambiental no ambiente escolar, os professores novamente foram unânimes em responder que é interessante a inserção da Educação Ambiental, no ambiente escolar, e que já desenvolveram também alguma atividade em sua disciplina.

Questionados sobre a participação em cursos voltados para a área ambiental, 33,5\% responderam já ter participado, enquanto $66,5 \%$ nunca participaram. Percebe-se que os professores têm o conhecimento sobre 0 
tema, mas a maioria nunca participou e nem lhes são oferecidas capacitações referentes à Educação Ambiental.

Sobre a frequência com que os assuntos de EA e meio ambiente são abordados em sua disciplina, $50 \%$ responderam raramente, $48 \%$ sempre que possível, e $2 \%$ frequentemente (Figura 10).

Percebeu-se, ainda, que a Educação Ambiental não está inserida no currículo, e que a mesma é trabalhada de forma isolada, em algumas disciplinas, especialmente as relacionadas com o meio ambiente, sendo que a transversalidade exigida pelos documentos oficiais, como os PCNs, não acontece.

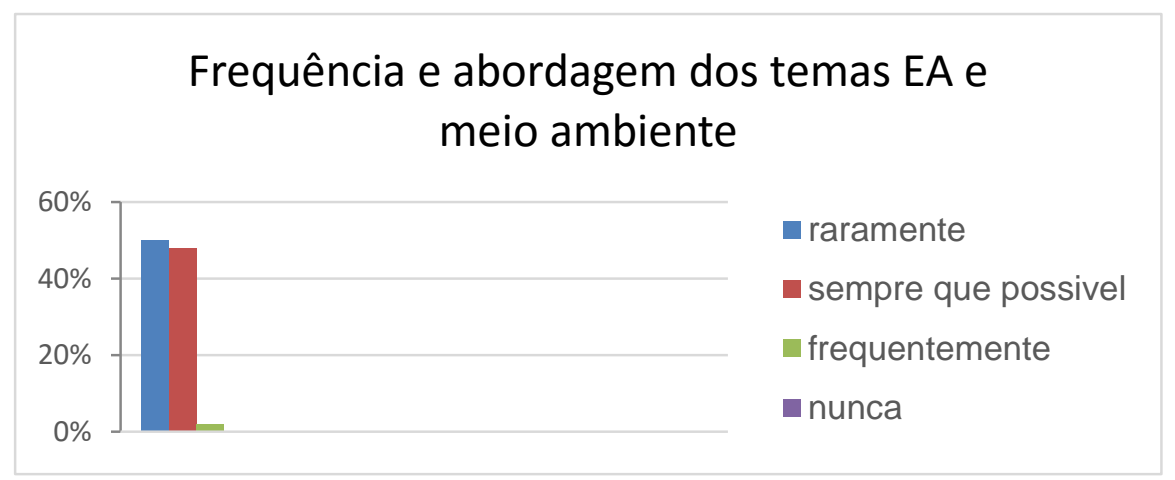

Figura 10: Frequência da abordagem dos temas relacionados à Educação Ambiental e meio ambiente de acordo com os professores da Escola Municipal Comendador Cortez em Parnaíba (PI), 2015.

De acordo com a interpretação da figura 10, causa estranheza considerar a Educação Ambiental como desnecessária, pois apenas 2\% abordam a temática com frequência. Considerando a importância da temática ambiental, é mister que se desenvolvam conteúdos, ou seja, meios que possam contribuir para a conscientização de que os problemas ambientais podem ser solucionados mediante uma postura participativa de professores, alunos e sociedade, uma vez que a escola deve proporcionar possibilidades de sensibilização e motivação para um envolvimento ativo de todos os seus atores.

Na questão 7, quando se investigou sobre os conteúdos relacionados a EA nos livros didáticos, apenas $16,6 \%$ dos professores confirmaram que existem conteúdos relacionados a EA nos livros didáticos de Ciências e Geografia.

Outros aspectos levantados na pesquisa mostram que $66,6 \%$ dos professores afirmaram que não se sentem motivados para desenvolver projetos de EA. Os professores questionam a falta de material didático, sendo que o próprio livro didático é carente de conteúdos relacionados à questão ambiental, se fazendo necessário outras metodologias com outros materiais que poderiam 
auxiliar, mas que a escola pesquisada não disponibiliza, tornando o trabalho ainda mais difícil. Além de que falta uma maior compreensão e colaboração por parte da comunidade escolar em colocar em prática ações que contribuam para a melhoria do meio ambiente.

$\mathrm{Na}$ questão 10, sobre os meios utilizados pela escola para desenvolver atividades de EA com os alunos, $75 \%$ dos professores afirmam que um dos meios utilizados para desenvolver algumas atividades com os alunos sobre EA, é a aula passeio, e 25\% afirmam ser pequenas exposições (Figura 11).

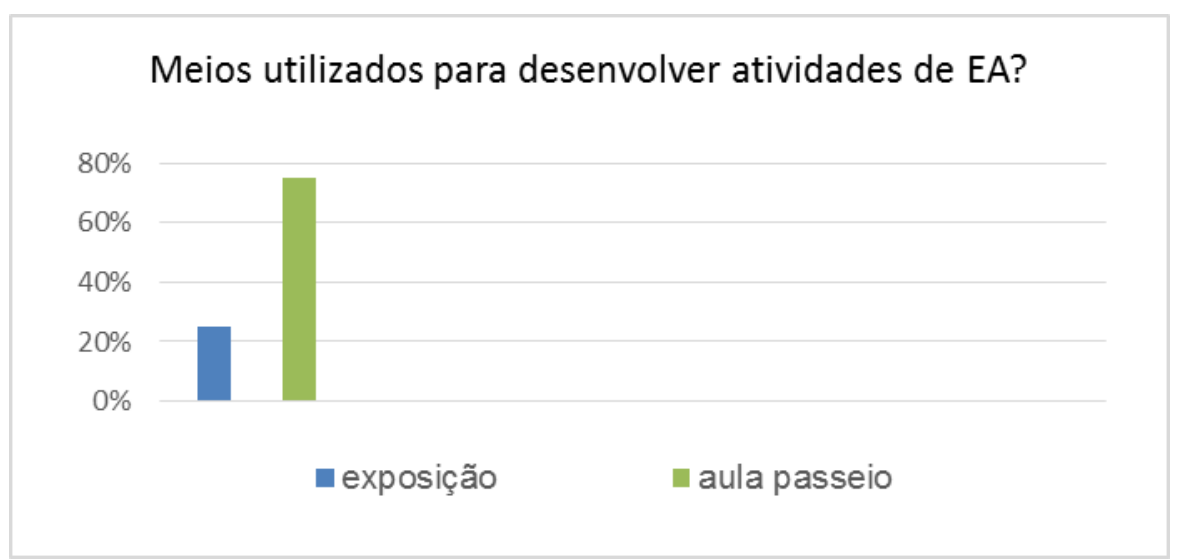

Figura 11: Formas de abordagem pelos professores para desenvolver atividades de EA na Escola Municipal Comendador Cortez em Parnaíba (PI), 2015.

Em uma pesquisa realizada em Escolas Estaduais de Floresta - PE mostrou-se que parte dos alunos de ensino médio tem uma noção sobre a questão Ambiental. No entanto, faz-se perceber que gestores e professores dificilmente saem do discurso e partem para prática, mostrou, ainda, que há uma grande carência de projetos voltados ao meio ambiente e em continuações de trabalhos relacionados ao tema (SÁ; OLIVEIRA; NOVAES, 2015).

Segundo ainda Sá, Oliveira e Novais (2015), os gestores/professores têm clareza quanto à importância dessa temática, mas há pouca consistência em relação à mesma, e ainda que, a maioria dos alunos tenham, interesse em aprender mais sobre Educação Ambiental. Percebe-se a necessidade de incentivá-la diariamente na escola, com reflexões e práticas que levem todos a compreender as questões ambientais, para que se possa formar cidadãos com consciência ambiental, facilitando, assim, sua vivência em sociedade. 
Conforme o exposto na Figura 11, entre os recursos mais utilizados para se desenvolver a Educação Ambiental, a aula passeio aparece como uma forte opção para auxiliar nas atividades de Educação Ambiental.

Sair da sala de aula e ir a campo com o objetivo de ter contato com o objeto de estudo é uma forma eficaz de pôr o aluno em contato com a realidade que o cerca. A sala de aula é uma grande ferramenta, que vem sendo utilizada durante muitas gerações, o que se precisa é investir na formação de professores que saibam utilizar todo e qualquer espaço para ensinar Educação Ambiental, sendo assim "o professor pode educar ambientalmente em qualquer lugar" (REIGOTA, 1994, p.30).

Nessa pesquisa ainda foram indagados outros temas relacionados à EA e meio ambiente, pois são assuntos recorrentes e de extrema importância para 0 aprendizado escolar. Assim, em sete perguntas os professores foram indagados se abordam os termos; biodiversidade, recursos naturais, unidade de conservação, conservação e preservação do solo, coleta seletiva de lixo, compostagem e movimentos ambientalistas.

Em relação aos temas relacionados à EA e meio ambientes que são abordados nas aulas dos professores, pode-se verificar que 0 de biodiversidade foi o mais citado com $35 \%$ das respostas, seguido de coleta seletiva do lixo com $23 \%$, e compostagem com $20 \%$, seguida ainda de recursos naturais com $13 \%, 5 \%$ para conservação e preservação do solo, $2 \%$ para unidades de conservação e $2 \%$ movimentos ambientalistas (Figura 12).

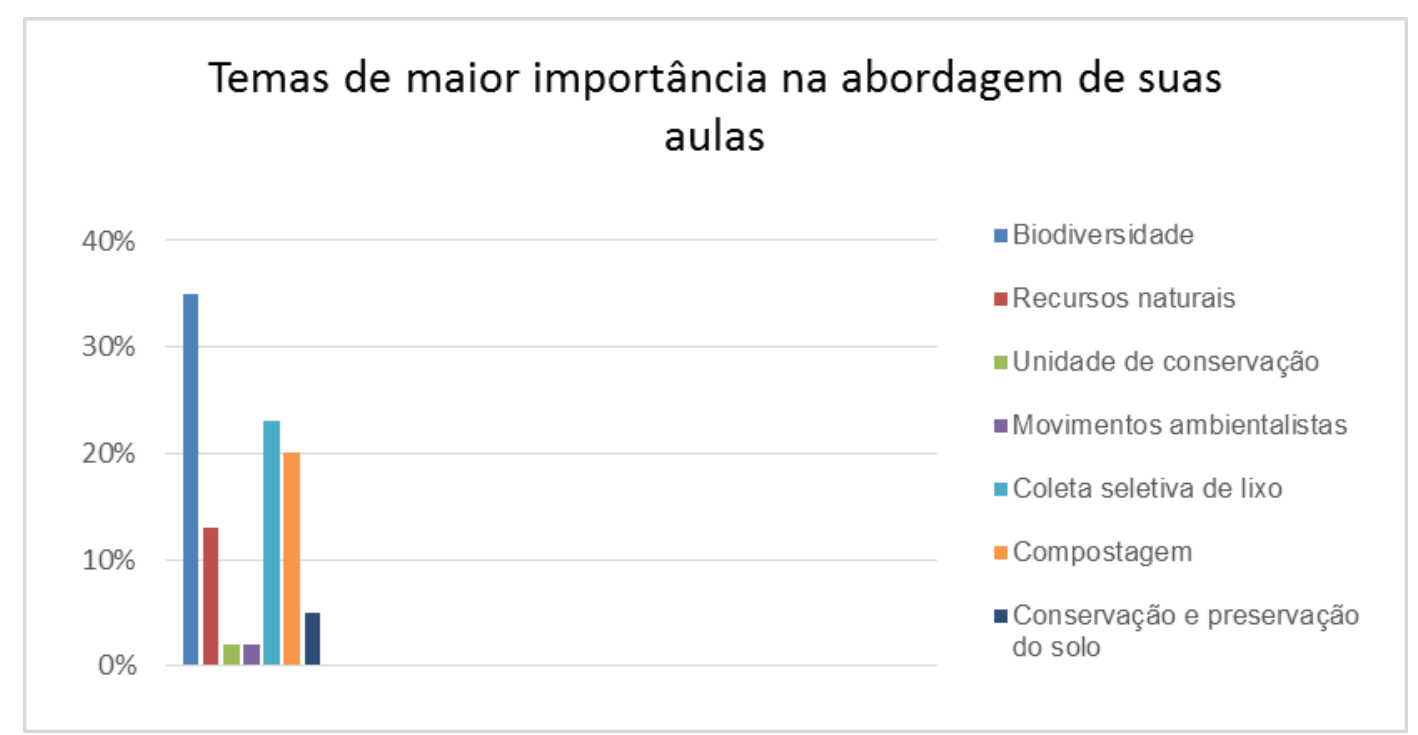

Figura 12: Temas relacionados à Educação Ambiental e Meio Ambiente trabalhados pelos professores na Escola Municipal Comendador Cortez, Parnaíba (PI), 2015.

Sabe-se que hoje os objetivos da Educação Ambiental só serão alcançados quando todos perceberem que este processo é algo que tem que ser entendido e realizado por cada um de nós, esse é o caminho para que cada Revbea, São Paulo, V. 11, № 2: 22-42, 2016. 
indivíduo mude seus hábitos e assuma novas atitudes que levem à diminuição da degradação ambiental, promovam a melhoria da qualidade de vida e reduzam a pressão sobre os recursos ambientais (SÁ; OLIVEIRA; NOVAES, 2015).

Percebe-se ainda que o tema de maior importância abordado pelos professores é biodiversidade como apresentado na Figura 12. Há também que se destacar que $23 \%$ citaram a coleta seletiva de lixo, e compostagem como sendo a terceira resposta mais citada. Para que esses temas ambientais apontados pelos professores possam ser abordados nas escolas com eficiência, de modo a desenvolver no meio deles uma conscientização ambiental e causar mudanças também no comportamento, é necessário que haja uma interdisciplinaridade, integrando conhecimentos de outras áreas do saber, além daquela em que as atividades são realizadas. Também é importante que haja uma relação do que é trabalhado em sala de aula com a realidade do aluno, com as problemáticas ambientais que fazem parte do seu convívio social, para que, assim, ele possa se sentir motivado a aprender cada vez mais.

Em um estudo realizado por Martins e Oliveira (2005) sobre Biodiversidade na Escola Municipal de Educação Básica (EMEB) de São Carlos-SP, identificaram que a temática é tratada de forma integrada e correlacionada entre as concepções apresentadas pelas professoras e estudantes nos componentes curriculares, favorecendo a interface entre a EA e o Ensino de Ciências. Além disso, verificaram, também, que, apesar dessa inter-relação, não há a proposição de projetos específicos sobre a temática, os quais potencialmente poderiam envolver as esferas políticas, sociais, culturais, éticas e econômicas, em uma perspectiva de Educação Ambiental crítica.

Para sanar essas dificuldades, os autores elaboraram estratégias como um conjunto de atividades e materiais didáticos envolvendo a temática para reflexão sobre conservação da biodiversidade na região do município. Hoje é notória a importância, tanto para construção do campo epistemológico da Educação Ambiental escolar, quanto para a formulação de práticas educativas, principalmente, numa perspectiva crítica que permite valorizar os elementos relacionados à biodiversidade do contexto social e cultural dos estudantes no sentido de permitir reflexão, transformação e emancipação dos sujeitos envolvidos.

Diante do exposto, este trabalho espera contribuir futuramente para um melhor entendimento acerca de como a EA está chegando aos alunos do Ensino Fundamental da Escola municipal Comendador Cortez, de Parnaíba $(\mathrm{PI})$, diante dos novos paradigmas que devem nortear a conduta dos professores ao tratar o tema Educação Ambiental. Foi ainda possível traçar o panorama de sua realidade quanto à exposição do tema, verificando ainda as práticas pedagógicas desenvolvidas, e como estas buscam promover a conscientização dos alunos. Percebeu-se, ainda a pouca valorização dos Parâmetros Curriculares Nacionais nessas práticas. 


\section{Considerações finais}

A Educação Ambiental deve atingir todos os cidadãos através de uma intervenção pedagógica participativa permanente, procurando incutir no educando uma consciência crítica sobre a problemática ambiental, na medida em que esta constituíra uma possibilidade de formar conceitos, atitudes e habilidades novas na relação sadia entre o homem e o meio ambiente;

Se o diagnóstico do ensino da Educação Ambiental na escola Municipal Comendador Cortez, Parnaíba (PI) apontou para um quadro de precariedade, reforçamos a ideia de que somente por meio da educação é que poderemos assegurar e preservar os interesses das futuras gerações.

A chave para o desenvolvimento na Educação Ambiental é a participação, o envolvimento de todos os interessados, a organização da coletividade e o fortalecimento das pessoas. Por isso, a Educação Ambiental não deverá apenas contemplar o desenvolvimento sustentável, os fatores econômicos. É necessário investir nas pessoas, na cultura, na história e nos sistemas sociais. A Educação Ambiental só é eficaz quando os alunos são capazes de empregar os conhecimentos adquiridos dentro da sala de aula em questões que surgirão no seu dia a dia.

Sendo a Educação Ambiental um processo amplo e complexo, faz-se necessário investir nas campanhas de conscientização ambiental através de atividades com a comunidade, quais sejam: caminhadas, semanas de meio ambiente, programa de orientação ambiental.

\section{Referências}

ANTUNES, M,A.M. Importância da Educação Ambiental. Instituto Teotônio Vilela, 2004.

BRASIL. Lei de Diretrizes e Bases da Educação Nacional, Lei oㅡ 9.394, de 20 de dezembro de 1996.

BRASIL. Parâmetros Curriculares Nacionais: Meio Ambiente e Saúde. Ministério da Educação. Secretaria da Educação Fundamental. 3. ed. Brasília: A Secretaria, 2001.

BRITTO, C. Educação e Gestão Ambiental. Salvador: Ministério do Meio Ambiente, 2000.

CARDOSO, F.A; FRENEdOSO, R.C; ARAÚJO, MS. T. Concepções de meio Ambiente entre estudantes de licenciatura em Ciências Biológicas. Revbea, São Paulo, V.10, No 2: 95-112, 2015.

GUIMARÃES, M. A dimensão Ambiental na educação. Campinas-SP: Papirus, 2005.

GUIMARÃES, M. Caminhos da Educação Ambiental da forma à ação. Campinas: Papirus, 2007. 
IBGE. Histórico da cidade de Parnaíba (PI). Disponível em: $<$ http://biblioteca.ibge.gov.br/visualizacao/dtbs/piaui/parnaiba.pdf $>$. Acesso em: maio de 2015.

JACOBI, P.R. Educação Ambiental, Cidadania e Sustentabilidade. USP: Educação e Pesquisa, São Paulo, N. 118, P. 189-205, março/2005.

LAYRARGUES, P.P. Identidade da Educação Ambiental brasileira. Ministério do Meio Ambiente / Diretoria de Educação Ambiental. Brasília: Ministério do Meio Ambiente, 2004.

LIPAI, E.M.; LAYRARGUES, P.P.P.; VAZZI, V. Educação Ambiental na escola: tá na lei. In: MELLO, S.S.; TRAJBER, R. Vamos cuidar do Brasil: conceitos e práticas em Educação Ambiental na escola. Brasília: MEC: MMA: UNESCO, 2007. p- 23-34.

Lei n. 9795 - 27 de abril de 1999. Dispõe sobre a Educação Ambiental. Política Nacional de Educação Ambiental. Brasília, 1999.

LIMA, W. Aprendizagem e classificação social: um desafio aos conceitos. Fórum Crítico da Educação: Revista do ISEP/Programa de Mestrado em Ciências Pedagógicas. v. 3, n. 1, out. 2004. Disponível em: $<$ http://www.isep.com.br/FORUM5.pdf>. Acesso em: 02.022015.

MARTINS, C; OLIVEIRA, H. T. Biodiversidade no contexto escolar: concepções e práticas em uma perspectiva de Educação Ambiental crítica. Revbea. São Paulo, V. 10, No 1: 127-145, 2015.

MEDEIROS, A. B. et al. A importância da Educação Ambiental na escola nas séries iniciais. Revista Faculdade Monte Belo. v. 4(1):1-17. 2011.

MEIRELLES, M. de S.; SANTOS, M. T. Educação Ambiental uma Construção Participativa. 2ª ed. São Paulo, 2005.

MORALES, A.G. Educação Ambiental em Busca de uma Sociedade Sustentável. 2004. Disponível em: <www.amigosdanatureza.org.br $>$. Acesso em: 02 de março 2015.

MAKNAMARA, M. Educação Ambiental e ensino de Ciências em escolas públicas alagoanas. Contrapontos - Volume 9 no 1 - pp. 55-64, 2009. Disponível em: <http://www.revistaea.org/artigo.php?idartigo=1869>. Acesso em: abril de 2015.

OLIVEIRA, E.G; SAITO, C.H. Análise do material didático Probio-Educação Ambiental com foco na Transversalidade curricular do tema meio ambiente. Revbea, São Paulo, V.9, № 2: 225-238, 2014.

OLIVEIRA, M.S.; OLIVEIRA, B.S.; VILELA, M.C.S.; CASTRO, T.A.A. Revista Científica Eletrônica de Ciências Sociais Aplicadas da Eduvale, Ano V, 07, 2012.

OTERO, P.B.G; NEIMAN, Z. Avanços e desafios da Educação Ambiental Brasileira entre a Rio 92 e a rio+20. Revbea. São Paulo, V. 10, No 1: 20-41, 2015.

revista brasileira educação ambiental 
REIGOTA, M. O que é Educação Ambiental? 1. Ed. São Paulo: Editora Brasiliense, 1994.

SÁ, M A; OLIVEIRA, M. A; NOVAES, A. S. R. Educação Ambiental nas Escolas estaduais de Floresta (PE). Revbea, São Paulo, V. 10, No 1: 118-126, 2015.

SOUSA, M.L.L; FERNANDES, A.C. Educação Ambiental em pau dos ferros (rn): em foco a Escola municipal professor Severino bezerra. Revbea, São Paulo, V 10, No 2: 318-343, 2015.

SOUSA, M.F. 2007. Educação Ambiental. Disponível em: $<$ <ww.ambientebrasil.com.br>. Acesso em: 20 de março, 2015.

BOSA, C.R.; TESSER, Halandey C.B. Desafios da Educação Ambiental nas escolas municipais do município de Caçador - SC. REMOA - Revista do Centro do Ciências Naturais e Exatas - UFSM, Santa Maria. V. 14, N. 2. 2014. março, p. 2996 - 3010. Disponível em: <http://cascavel.ufsm.br/revistas/ojs2.2.2/index.php/remoa/article/view/9763/pdf>. Acesso em: maio de 2015.

SANTOS, E.T.A. Educação Ambiental na escola: conscientização da necessidade de proteção da camada de ozônio. 51f. 2007. Monografia (Especialização em Educação Ambiental) Curso de Pós-Graduação em Educação Ambiental da Universidade Federal de Santa Maria UFSM, RS. Santa Maria, RS.

UNESCO. Década da Educação das Nações Unidas para um Desenvolvimento Sustentável, 2005-2014: documento final do esquema internacional de implementação, Brasília, Brasil, 2005.

ZUBEN, F.V. Meio Ambiente, Cidadania e Educação. Departamento de Multimeios. Unicamp. Tetra Pak Ltda. 1998. Disponível em: $<$ http://www.planetareciclavel.com.br/sala de aula/Tetra Pak/Cadernos do $\mathrm{pr}$ ofessor.pdf>. Acesso em: junho de 2015. 